\title{
Quantitative Determination of Brexpiprazole by RP-HPLC Method
}

\author{
Veera S. Pulusu ${ }^{1^{*}}$, Krishna C. Routhu ${ }^{2}$ and Soma SB. Chikkaswamy ${ }^{3}$ \\ ${ }^{1}$ Department of Chemistry, Swami Ramanand Teerth Marathwada University, Maharashtra, India \\ ${ }^{2}$ Pharmaceutics, GITAM Institute of Pharmacy, GITAM University, Visakhapatnam, Andhra Pradesh, India \\ ${ }^{3}$ Department of Chemistry, University of Mysore, Manasagangotri, Mysore, India
}

\begin{abstract}
A stability-indicating RP-HPLC method was established and validated for the determination of Brexpiprazole in bulk drug using C18 column Waters $(150 \mathrm{~mm} \times 4.6 \mathrm{~mm}, 5 \mu \mathrm{m})$ with a mobile phase containing of $500 \mathrm{~mL}$ of $10 \mathrm{mM}$ monobasic Potassium phosphate buffer adjusted $\mathrm{pH} 2.0$ with $85 \%$ Orthophosphoric acid and $500 \mathrm{~mL}$ of HPLC grade Acetonitrile. The mobile phase was filtered with a 0.45 $\mu \mathrm{m}$ membrane filter and degassed by sonicating for few minutes. The detection was performed at $213 \mathrm{~nm}$ using a Photodiode Array Detector at a flow rate of $1.0 \mathrm{~mL} \mathrm{~min}{ }^{-1}$ and Brexpiprazole was eluted at $2.5 \mathrm{~min}$. with column temperature $30^{\circ} \mathrm{C}$. The detector response was generated from the concentration range of $0.01-0.06 \mathrm{mg} \mathrm{mL}^{-1}$ and regression coefficient $(\mathrm{r})$ was 0.999 . Brexpiprazole was exposed to stress conditions such as acidic, basic, oxidation, hydrolysis, photolysis and thermal degradation, and the outcomes showed that the molecule was more sensitive to peroxide degradation. This method was validated as per ICH and FDA guidelines and showed linearity, accuracy, precision, specificity, robustness, LOD, LOQ and system suitability results within the acceptance criteria.
\end{abstract}

Keywords: Brexpiprazole; Isocratic; RP-HPLC; Stability-indicating; Development; Validation

\section{INTRODUCTION}

Brexpiprazole is a serotonergic-noradrenegic-dopaminergic acting compound. It is a small molecule with molecular formula $\mathrm{C}_{25} \mathrm{H}_{27} \mathrm{~N}_{3} \mathrm{O}_{2} \mathrm{~S}$, molecular weight $433.57 \mathrm{~g} / \mathrm{mol}$ and chemically known as 7-\{4-[4-(1-Benzothiophen-4-yl)piperazin-1-yl]butoxy\} quinoline-2(iH)-one Brexpiprazole is non-hygroscopic, with white to off white crystalline powder and a melting point of $183^{\circ} \mathrm{C}$ (decomposition) [1]. This is a weakly basic compound with a $\mathrm{pKa}$ of 7.8 and this drug is not soluble in water. Brexpiprazole (Figure 1) is used in treatment of schizophrenia and adjunctive treatment of Major Depressive Disorder (MDD) [2]. It has partial agonistic activity at serotonegic 5-HT1A and at dopaminergic D2 receptors, antagonistic activities at serotonergic 5-HT2A, and antagonist activity at noradrenergic $\alpha_{1 / 2}$ receptors [2].

Literature survey revealed that Brexpiprazole was determined by UV-visible spectroscopy [3] and HPLC [4-7]. In the current work, the authors have proposed a simple, specific, valid and robust RP-HPLC method for the estimation of Brexpiprazole in pharmaceutical active substance form.

\section{METHODOLOGY}

\section{Chemicals and solvents}

Brexpiprazole standard (Purity $\geq 99.7$ as is basis), Acetonitrile (HPLC grade), HPLC grade water (Millipore), Potassium phosphate monobasic, 85\% Orthophosphoric acid, Sodium hydroxide, Hydrochloric acid and Hydrogen peroxide were purchased from Merck.

\section{Instrumentation}

The instrument employed in the present work were analytical micro balance (Make: Mettler Toledo, Model: XP56), sonicator (Make: Elma, Model: S300H), hot air oven (Make: Servewell Instruments, Model: H02436), digital pH meter (Make: Mettler Toledo) and UVVisible chamber (Make: Mack Equipment, Model: MK-2). HPLC (Waters, 2695 with PDA detector 2996) and empower software.

\section{Method development}

Optimization of the chromatographic conditions: Several mobile phases containing Acetonitrile, different $\mathrm{pH}$ buffers in different proportions were tried with different column temperature. Mobile phase was prepared by combining $500 \mathrm{~mL}$ of $10 \mathrm{mM}$ monobasic Potassium Phosphate buffer, $\mathrm{pH}$ was adjusted to 2.0 with $85 \%$ Orthophosphoric acid and $500 \mathrm{~mL}$ of Acetonitrile. The mobile phase was filtered and de-gassed by sonication. Symmetrical peak was found with Waters C18 column $(150 \mathrm{~mm} \times 4.6 \mathrm{~mm}, 5 \mu \mathrm{m})$ at $30^{\circ} \mathrm{C}$. The flow rate was $1.0 \mathrm{~mL} / \mathrm{min}$ and wavelength was set at 213 $\mathrm{nm}$. All determinations were performed at ambient temperature for a run time of $5 \mathrm{~min}$. with $10 \mu \mathrm{L}$ injection volume.

Preparation of working standard solution: The standard solution of Brexpiprazole prepared as $20 \mathrm{mg}$ of pure drug was dissolved in $50 \mathrm{~mL}$ volumetric flask and diluted to volume with mobile phase (Stock concentration $0.4 \mathrm{mg} \mathrm{mL}^{-1}$ ). Further $5.0 \mathrm{~mL}$ of stock was diluted to $50 \mathrm{~mL}$ with mobile phase and mixed (working std.

Correspondence to: Pulusu VS, Department of Chemistry, Swami Ramanand Teerth Marathwada University, Maharashtra, India, Tel: 2419450; E-mail: veerashakar@gmail.com

Received: April 19, 2019; Accepted: May 22, 2019; Published: May 29, 2019

Citation: Pulusu VS, Routhu KC, Chikkaswamy SSB (2019) Quantitative Determination of Brexpiprazole by RP-HPLC Method. Pharm Anal Acta 10:610. doi: 10.35248/2153-2435.19.10.610

Copyright: (C) 2019 Pulusu VS, et al. This is an open-access article distributed under the terms of the Creative Commons Attribution License, which permits unrestricted use, distribution, and reproduction in any medium, provided the original author and source are credited. 
concentration $0.04 \mu \mathrm{g} \mathrm{mL}-1$ ). The representative chromatogram and peak purity curve of Brexpiprazole were shown in Figures 2 and 3 for the proposed method.

\section{Method validation}

The current developed method was validated according to $\mathrm{ICH}$ and FDA guidelines by evaluating linearity, precision (method and intermediate), accuracy, LOD, LOQ, degradation and robustness.

Specificity: Forced degradation study was established by exposing drug substance samples to various stress conditions. Stressed samples were evaluated, active peak was checked for the retention time, peaks interference and spectra purity.

Linearity: A stock solution of Brexpiprazole of $400 \mu \mathrm{g} \mathrm{mL} \mathrm{m}^{-1}$ was prepared using the mobile phase as solvent. From the above stock, a series of solutions were prepared from 10 to $60 \mu \mathrm{gL}^{-1}$. In this experiment triplicate injections of each concentration were analyzed and linearity graph was plotted Brexpiprazole concentration vs. peak area.

Accuracy: The accuracy of the developed method was achieved by the addition of known amounts of drug by weight in triplicate $(50 \%, 100 \%$ and $150 \%)$ around the test concentration, by nine determinations (triplicate preparations of each level). The percentage accuracy and the RSD were calculated for each level to measure how close the experimental value is to the true value.

Precision: Precision was evaluated at two levels, method precision and intermediate precision. Method precision or repeatability was determined by six assay determinations at the $100 \%$ test concentration level on the same day. The RSD of obtained results was calculated to estimate method precision results.

Intermediate precision (inter-assay variation) was determined by doing another analyst on a different day and using different equipment. The RSD of combined results obtained by both analysts were calculated to evaluate intermediate precision.

\section{Detection limit and quantification limit:}

The Detection Limit (DL) may be expressed as: $\mathrm{DL}=3.3 \sigma / \mathrm{S}[8]$

The Quantification Limit (QL) may be expressed as: QL=10 $\sigma / \mathrm{S}$ [8]

Where, $\sigma$ is the standard deviation of the response, and " $S$ " is the slope of the calibration curve [8].

The slope $\mathrm{S}$ may be estimated from the calibration curve of the analyte. The estimation of $\sigma$ may be carried out with based on standard deviation of the blank or based on the calibration curve [8].

Robustness: Robustness was established by applying small changes of the following method conditions

1. Flow rate: $\pm 0.2 \mathrm{~mL} \mathrm{~min}^{-1}$

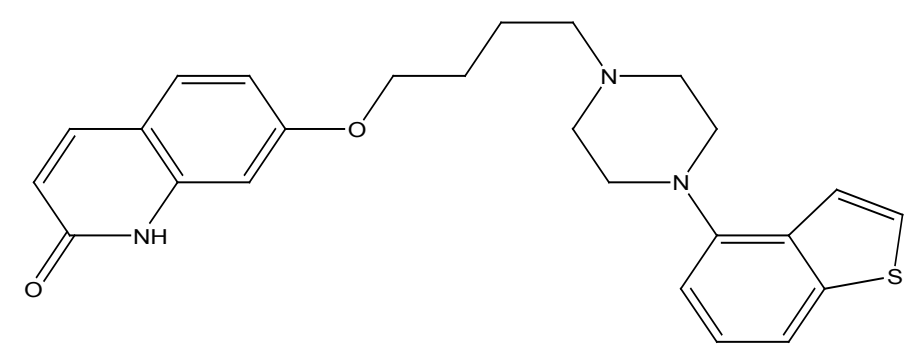

Figure 1: Chemical structure of Brexpiprazole.

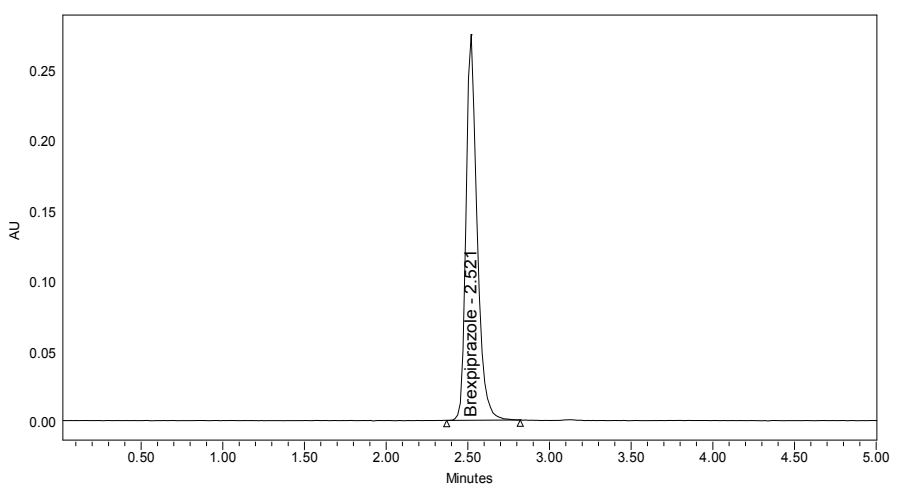

Figure 2: Typical chromatograms of Brexpiprazole under optimised conditions.

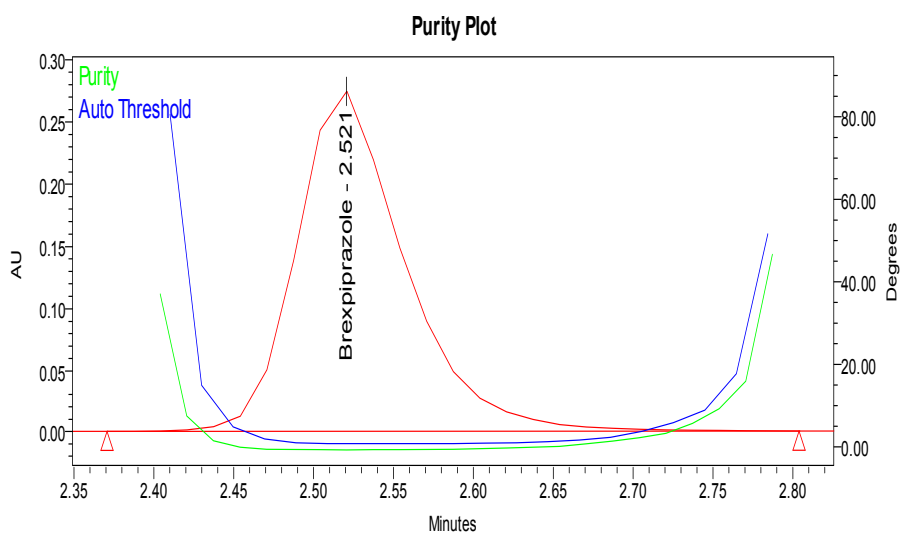

Figure 3: Peak purity curves of Brexpiprazole under optimised conditions.

2. Column temperature: $\pm 5^{\circ} \mathrm{C}$

3. Variation in mobile phase organic composition $\pm 10 \%$ (absolute)

Standard solution was analyzed for each variation. Change was made to estimate its effect on the developed method. Acquired data for each case was evaluated by calculating \% RSD, Retention Time (RT), USP tailing and plate count.

\section{Forced degradation studies}

The International Conference on Harmonization (ICH) Q1B guideline [9] provides guidance for performing photostability testing of new drug substances and products. Typical forced stress tests include four main degradation procedures: hydrolytic, oxidative, heat and photolytic degradation [10]. Selecting suitable reagents such as the concentration of acid, base and varying the conditions and length of exposure can achieve the ideal level of degradation [11]. The active substance was exposed to these conditions, and the main peak studied for the peak purity, thus including that the method efficiently separated the degradation products from the active substance. Typical overlay of chromatogram obtained following the assay of stressed samples is shown in (Figure 4).

Acid and base hydrolysis degradation: Acid and base stress study was performed to force the degradation of the drug substance to its potential degradation products by exposure to acidic, basic and neutral conditions. Hydrolysis is the chemical breakdown of substances by water and depends on the chemistry, solubility, $\mathrm{pH}$, and the oxidation reduction potential of a compound. The possible functional groups undergo hydrolysis are amides, esters, alcohols and imines [10]. Hydrolysis of an amide breaks the carbon-nitrogen bond and produces an acid and either ammonia or an amine. Ester 
hydrolysis occurs comparatively easily, but amides resist hydrolysis. Acidic hydrolytic stress of Brexpiprazole was performed using $0.1 \mathrm{M}$ Hydrochloric acid. Weighed and transferred about twenty micrograms of Brexpiprazole active substance into a $50 \mathrm{~mL}$ volumetric flask. Added $5.0 \mathrm{~mL}$ of $0.1 \mathrm{M} \mathrm{HCl}$ and kept in water bath at $80^{\circ} \mathrm{C}$ for 5 hours. After that immediately neutralized with 5.0 $\mathrm{mL}$ of $0.1 \mathrm{M}$ Sodium hydroxide and attained to room temperature. Dissolved and diluted to volume with mobile phase and mixed. Further diluted $5.0 \mathrm{~mL}$ to $50 \mathrm{~mL}$ with mobile phase and mixed. The obtained chromatogram was analyzed for any degradation occurred during the process. The results are summarized in Table 1.

Base degradation of Brexpiprazole was performed using 0.1 M Sodium hydroxide. Weighed about twenty micrograms of Brexpiprazole active substance and transferred into a $50 \mathrm{~mL}$ volumetric flask. Added $5.0 \mathrm{~mL}$ of $0.1 \mathrm{M} \mathrm{NaCl}$ and kept in water bath at $80^{\circ} \mathrm{C}$ for 5 hours. After that immediately neutralized with $5.0 \mathrm{~mL}$ of $0.1 \mathrm{M} \mathrm{HCl}$ and attained to room temperature. Dissolved in and diluted to volume with mobile phase and mixed. Further diluted $5.0 \mathrm{~mL}$ to $50 \mathrm{~mL}$ with mobile phase and mixed. The obtained chromatogram was analyzed for any degradation occurred during the process. The results are given in Table 1.

Oxidation degradation: Different concentration of Hydrogen peroxide is generally using in oxidative stress study. Although hydrogen peroxide is used mostly because it mimics possible presence of peroxides in excipients, other oxidizing agents such as metal ions, oxygen, and radical initiators can be used [11]. Selection of oxidizing agents, its concentration, and conditions depends on the nature of the drug substance [11].

Peroxide degradation of Brexpiprazole was performed using 3\% Hydrogen peroxide. Weighed about twenty micrograms of Brexpiprazole drug substance and transferred into a $50 \mathrm{~mL}$ volumetric flask. Added $5.0 \mathrm{~mL}$ of $3 \%$ Hydrogen peroxide and kept in water bath at $60^{\circ} \mathrm{C}$ for 3 hours. After the attained room temperature, dissolved in and diluted to volume with mobile phase, and mixed. Further diluted $5.0 \mathrm{~mL}$ to $50 \mathrm{~mL}$ with mobile phase and mixed. Injected immediately into HPLC to avoid further

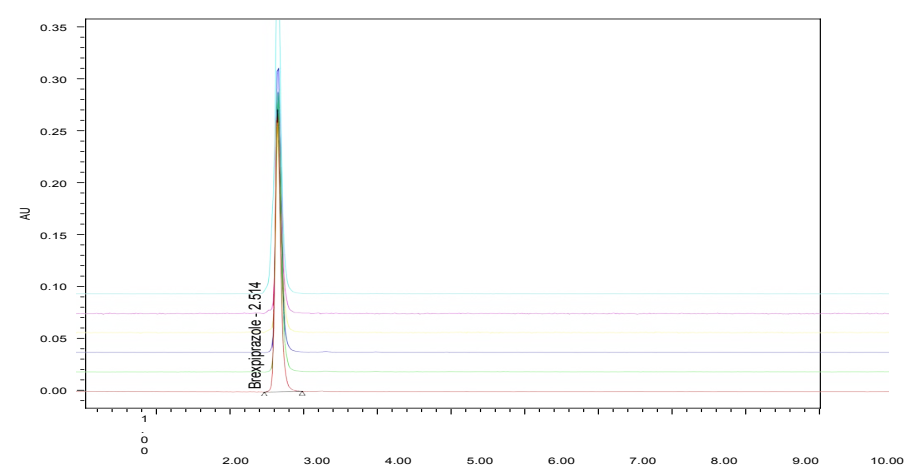

Figure 4: Typical overlay chromatogram of Brexpiprazole on acidic, basic, oxidative, thermal, photolytic and hydrolysis degradation. degradation. The obtained chromatogram was analyzed for any degradation occurred during the process. The results are given in Table 1.

Photolytic degradation: Photostability stress study should be an essential part of degradation, especially for photo-labile molecules. Samples of active drug substance, and solid drug product, should be exposed to a minimum of 1.2 million lux hours and 200-watt hours per square meter light [11]. The same sample should be exposed to both white and UV light. Temperature control may be necessary to minimize the effect of temperature changes during exposure [11].

Brexpiprazole drug substance was exposed to light about $1.2 \times 10^{6}$ lux-hours. The exposed drug was weighed about twenty micrograms and transferred into a $50 \mathrm{~mL}$ volumetric flask. Dissolved in and diluted to volume with mobile phase, and mixed. Further diluted $5.0 \mathrm{~mL}$ to $50 \mathrm{~mL}$ with mobile phase and mixed. The obtained chromatogram was analyzed for any degradation occurred during the process. The results are given in Table 1 .

Thermal degradation: Thermal degradation testing conditions should be higher than recommended ICH Q1 Aaccelerated testing conditions [12]. Samples of solid-state drug substances and finished products should be exposed to dry heat and wet heat, whereas liquid drug products can be exposed to dry heat. Thermal degradation study is recommended that the effect of temperature be studied in $10^{\circ} \mathrm{C}$ gradual increment above that for routine accelerated testing, and humidity at $75 \%$ relative humidity or greater [11].

Thermal degradation was performed by treating the Brexpiprazole drug substance at $40^{\circ} \mathrm{C} / 75 \% \mathrm{RH}$ for 14 days in an open container. Weighed about twenty micrograms of above treated Brexpiprazole drug substance and transferred into a $50 \mathrm{~mL}$ volumetric flask. Dissolved in and diluted to volume with mobile phase, and mixed. Further diluted $5.0 \mathrm{~mL}$ to $50 \mathrm{~mL}$ with mobile phase and mixed. The obtained chromatogram was analyzed for any degradation occurred during the process. The results are given in Table 1 .

Hydrolysis degradation: Hydrolysis degradation of Brexpiprazole drug substance was performed using distilled water. Weighed about twenty micrograms of Brexpiprazole substance and transferred into a $50 \mathrm{~mL}$ volumetric flask. Added $5.0 \mathrm{~mL}$ of distilled water and dissolved the drug. Then the volumetric flask was heated in a water bath at $80^{\circ} \mathrm{C}$ for 3 hours. After attaining to room temperature, flask was diluted to volume with mobile phase and mixed. Further diluted $5.0 \mathrm{~mL}$ to $50 \mathrm{~mL}$ with mobile phase and mixed. The obtained chromatogram was analyzed for any degradation that could have occurred during the process. The results are given in Table 1.

\section{RESULTS}

\section{Method development}

The developed chromatographic conditions were optimized to

Table 1: Results of degradation

\begin{tabular}{cccccccc}
\hline Sr. No & Name of Degradation & RT $(\mathrm{min})$ & Area & Purity angle & Purity threshold & \% Degradation \\
\hline 1 & Acid degradation & 2.514 & 1229713 & 0.171 & 0.298 & 4.6 \\
\hline 2 & Base degradation & 2.522 & 1235426 & 0.159 & 0.303 & 0.300 & 0.1 \\
\hline 3 & Peroxide degradation & 2.522 & 1208131 & 0.176 & 0.345 & 0 \\
\hline 4 & Thermal degradation & 2.527 & 1259620 & 0.223 & 0.340 & 0.8 \\
\hline 5 & UV degradation & 2.526 & 1276153 & 0.210 & 0.302 & 0.2 \\
\hline 6 & Hydrolysis degradation & 2.518 & 1285933 & 0.259 & & 0 \\
\hline
\end{tabular}


determine Brexpiprazole in drug substance and dosage form. Symmetrical peak was found with Waters C18 (150 mm×4.6 mm, 5 $\mu \mathrm{m})$ column at $30^{\circ} \mathrm{C}$ and mobile phase was consisted of Acetonitrile: $10 \mathrm{mM}$ monobasic potassium phosphate buffer, pH 2.0 with $85 \%$ Orthophosphoric acid (50:50, \%). Detector performed at $213 \mathrm{~nm}$ and flow rate was $1.0 \mathrm{~mL} / \mathrm{min}$. The injection volume was $10 \mu \mathrm{L}$ and the run time was $5 \mathrm{~min}$.

\section{Method validation}

Linearity: The linearity was performed using a calibration curve to check the capability of the analytical method to get a proportional response to the analyte concentration in the sample. The working sample (Method \& Intermediate precision) concentration and samples tested for accuracy were in the linear range. Standard stock was used as linearity stock and prepared 0.01 to $0.06 \mathrm{mg} \mathrm{mL}^{-1}$ solutions. The linearity was performed at six different concentrations in triplicate. The regression equation was determined as $y=3.1 x+9163.4$ and regression coefficient $(r)$ was 0.999 .

Precision: The Method precision and Intermediate precision (ruggedness) was prepared and evaluated six samples at $100 \%$ of the target sample concentration as per method. The results of \% assay and \% RSD are presented in Table 2.

Accuracy: The recovery of the method was determined by analyzing samples at three different levels of concentrations by spiking Brexpiprazole active substances. The \% recovery results are showed in below Table 3 .

This method was demonstrated to be accurate for the range from $50 \%$ to $150 \%$ of the sample concentration.
LOD and LOQ: The Limit of Detection (LOD) is the lowest concentration of analyte in a sample that can be detected, but not necessarily quantitated [8], while the Limit of Quantification (LOQ) is the lowest concentration of analyte in a sample that can be determined with acceptable precision and accuracy [8]. The current method showed a LOD of $0.10 \mu \mathrm{g} \mathrm{mL}^{-1}$ and LOQ of 0.30 $\mu \mathrm{g} \mathrm{mL}{ }^{-1}$ respectively and indicating method was extremely rugged.

\section{Forced degradation studies}

These stress conditions produce minute or no degradation due to the nature of a drug molecule. The nature of degradation depends on the functional groups of the drug molecule and the effect of stress conditions.

\section{Robustness}

Robustness of the method was studied by small variation of the chromatographic conditions such as flow $(1.0 \pm 0.2 \mathrm{~mL} / \mathrm{min})$, column temperature $\left(30 \pm 5^{\circ} \mathrm{C}\right)$ and mobile phase composition $( \pm 10 \%$ absolute). The results are given in Table 4 .

Variation in flow rate, mobile phase composition and column temperature do not affect the ability of the method to meet system analysis requirements (plate counts and tailing factor) and none of the above variations resulted in critical changes to the system analysis parameters.

\section{DISCUSSION}

In this RP-HPLC method, the linearity was within the range of 10$60 \mu \mathrm{g} \mathrm{mL}$ and regression equation were found to be $\mathrm{y}=3.1 \mathrm{x}+9163.4$

Table 2: Results of method precision and intermediate precision (ruggedness).

\begin{tabular}{|c|c|c|c|c|c|}
\hline \multirow[t]{2}{*}{ Sample no. } & \multirow[t]{2}{*}{ Conc. $(\mu \mathrm{g} / \mathrm{mL})$} & \multicolumn{2}{|c|}{ Method Precision } & \multicolumn{2}{|c|}{ Intermediate precision } \\
\hline & & Peak area & \% Assay & Peak area & \% Assay \\
\hline 1 & 40 & 1298524 & 100.0 & 1280779 & 99.9 \\
\hline 2 & 40 & 1281184 & 99.7 & 1283582 & 99.8 \\
\hline 3 & 40 & 1284808 & 99.8 & 1286481 & 100.1 \\
\hline 4 & 40 & 1277418 & 99.8 & 1281706 & 100.0 \\
\hline 5 & 40 & 1276845 & 99.7 & 1282942 & 99.8 \\
\hline \multirow[t]{3}{*}{6} & 40 & 1283383 & 99.8 & 1285584 & 99.9 \\
\hline & & Average & 99.8 & & 99.9 \\
\hline & & \% RSD & 0.10 & & 0.10 \\
\hline
\end{tabular}

Table 3: Recovery of Brexpiprazole drug substance summary.

\begin{tabular}{|c|c|c|c|c|c|c|c|}
\hline Sr. No & Recovery level \% & Mg Added (spiked) & mg Found & \% Recovery & Mean & SD & $\%$ RSD \\
\hline 1 & $50 \%-1$ & 9.99 & 9.964 & 99.7 & \multirow{3}{*}{99.8} & \multirow{3}{*}{0.1155} & \multirow{3}{*}{0.12} \\
\hline 2 & $50 \%-2$ & 9.96 & 9.948 & 99.9 & & & \\
\hline 3 & $50 \%-3$ & 10.02 & 9.991 & 99.7 & & & \\
\hline 4 & $100 \%-1$ & 19.64 & 19.637 & 100.0 & \multirow{3}{*}{99.9} & \multirow{3}{*}{0.1528} & \multirow{3}{*}{0.15} \\
\hline 5 & $100 \%-2$ & 19.74 & 19.688 & 99.7 & & & \\
\hline 6 & $100 \%-3$ & 19.73 & 19.706 & 99.9 & & & \\
\hline 7 & $150 \%-1$ & 29.28 & 29.243 & 99.9 & \multirow{3}{*}{99.9} & \multirow{3}{*}{0.0577} & \multirow{3}{*}{0.06} \\
\hline 8 & $150 \%-2$ & 29.42 & 29.385 & 99.9 & & & \\
\hline 9 & $150 \%-3$ & 29.47 & 29.461 & 100.0 & & & \\
\hline
\end{tabular}


Table 4: Robustness data of the RP-HPLC method at different flow rates for Brexpiprazole.

\begin{tabular}{|c|c|c|c|c|c|}
\hline Parameters & Modification & $\mathrm{RT}(\min )$ & Area & USPP late count & USP tailing \\
\hline \multirow{3}{*}{ Flow rate } & $0.8 \mathrm{~mL} / \mathrm{min}$ & 2.833 & 1460308 & 6983 & 1.16 \\
\hline & Optimized & 2.524 & 1290266 & 6569 & 1.18 \\
\hline & $1.2 \mathrm{~mL} / \mathrm{min}$ & 2.283 & 1163934 & 6659 & 1.16 \\
\hline \multirow{3}{*}{ Mobile phase composition } & $5 \%$ less & 2.498 & 1294719 & 6477 & 1.17 \\
\hline & Optimized & 2.524 & 1290266 & 6569 & 1.18 \\
\hline & $5 \%$ more & 2.555 & 1303388 & 6651 & 1.18 \\
\hline \multirow{3}{*}{ Column temperature } & $25^{\circ} \mathrm{C}$ & 2.546 & 1312629 & 6764 & 1.17 \\
\hline & Optimized & 2.524 & 1290266 & 6569 & 1.18 \\
\hline & $35^{\circ} \mathrm{C}$ & 2.505 & 1310603 & 6648 & 1.19 \\
\hline
\end{tabular}

Note: RT (min), area counts, USP plate count and USP tailing values are in average

with regression coefficient (r) 0.999. The method was successfully validated in the optimized conditions, and the validation parameters were within the specified limits. In this developed and validated RP-HPLC method, the LOD and LOQ of Brexpiprazole were found to be $0.1 \mu \mathrm{g} \mathrm{mL}^{-1}$ and $0.3 \mu \mathrm{g} \mathrm{mL}^{-1}$, respectively.

The RSD in precision experiment was found to be $0.10 \%$ (Intraday) and $0.10 \%$ (Inter-day). The \% RSD in accuracy and robustness experiments was found to be less than $2.0 \%$, indicating that the method is precise and accurate.

The theoretical plates were above 6500 (more than 2000) and tailing factor was 1.19 (less than 2.0) for Brexpiprazole peak. The \% RSD value of assay determination was less than $2.0 \%$, indicating that the developed method was robust.

In the current experiment, degradation of Brexpiprazole was carried out as per the ICH guidelines. The result of peroxide stress showed that $6.1 \%$ of degradation of the drug occurred when the drug substance was treated with $3 \%$ peroxide and kept in water bath at $60^{\circ} \mathrm{C}$ for 3 hours. In the hydrolysis degradation study, Brexpiprazole showed no degradation at $80^{\circ} \mathrm{C}$ for 3 hours.

\section{CONCLUSION}

This study is an example of development of a stability indicating assay, established following the recommendations of $\mathrm{ICH} / \mathrm{FDA}$ guidelines.

The proposed method showed acceptable precision, accuracy, sensitivity (LOD and LOQ) and wide linear concentration range. The established RP-HPLC method was found to be reliable for the analysis of Brexpiprazole, and was found to be simple, consistent, cost-effective and precise.

Therefore, this RP-HPLC method for determination of Brexpiprazole can be used in quality control or routine for its quantitative determination in bulk and pharmaceutical dosage form.

\section{REFERENCES}

1. Diefenderfer LA, Iuppa C. Brexpiprazole: A review of a new treatment option for schizophrenia and major depressive disorder. Ment Health Clinician. 2017;7:207-212.

2. Citrome L, Stensbøl TB, Maeda K. The preclinical profile of Brexpiprazole: what is its clinical relevance for the treatment of psychiatric disorders? Expert Rev Neurother. 2015;15:1219-1229.

3. Thakkar AM, Chhalotiya UK, Parekh N, Desai JV, Dalwadi HB, Shah DA. Quantification of Brexpiprazole in bulk and its pharmaceutical dosage form by UV-visible spectroscopic and SIAM RP-LC method. Austin Chromatogr. 2018;5:1050-1058.

4. Sravani A, Naga Durga CH, Uppalapati D, Suneetha $\mathrm{CH}$, Suresh P, Tirumaleswara RT, et al. Method development and validation for the estimation of Brexpiprazole in drug substance By Rp-Hplc method. Indo Am J Pharm Res. 2017;7:8560-8565.

5. Nehal PB, Ashok BP, Rao MS, Amit JV, Nilesh KP, Ajay P. Development and validation of stability indicating assay method and characterization of degradation product for Brexpiprazole bulk by RP-HPLC. J Chem Pharm Res. 2018;10:55-66.

6. Sowjanya B, Rambabu K. Development and validation for the simultaneous estimation of Brexpiprazole and fluoxetine in drug substance by RP-HPLC. Euro J Biomed Pharm Sci. 2018;5:411-417.

7. Amit G, Rajendra P. Gradient high-performance liquid chromatography method for determination of related substances in Brexpiprazole API. Int J Dev Res. 2018;8:21416-21424.

8. https://www.gmp-compliance.org/guidelines/gmp-guideline/ich-q2r1validation-of-analytical-procedures-text-and-methodology

9. https://www.fda.gov/regulatory-information/search-fda-guidancedocuments/q1b-photostability-testing-new-drug-substances-andproducts

10. Dey S, Patro SS, Suresh Babu N, Murthy NP, Panda KS. Development and validation of a stability-indicating RP-HPLC method for estimation of atazanavir sulfate in bulk. J Pharm Anal. 2017;7:134-140.

11.http://www.pharmtech.com/fda-perspectives-scientific-considerations-forced-degradation-studies-andasubmissions? $\mathrm{id}=\&$ sk $=\&$ date $=\&$ page $\mathrm{ID}=2$

12.https://www.fda.gov/regulatory-information/search-fda-guidancedocuments/q1ar2-stability-testing-new-drug-substances-and-products 